\title{
М.В. Макарова
}

\section{Интеллектуальное моделирование E-готовности информационной экономики}

\footnotetext{
Рассмотрены принципы когнитивного моделирования и когнитивная модель готовности страны к информационной экономике ( $E$-готовности). Проведена экспертная формализация модели применительно к Украине, дана оценка начального вектора управляющего воздействия на $E$-готовность и интерпретированы результаты его приложения. Проведен мониторинг изменения базисных факторов когнитивной модели с появлением новых технологий и изменениями в социально-экономической жизни Украины.

Ключевые слова: когнитивное моделирование, вектор управляющего воздействия, $E$-готовность, факторы когнитивной модели.

Розглянуто принципи когнітивного моделювання та когнітивна модель готовності країни до інформаційної економіки (E-готовності). Проведено експертну формалізацію моделі стосовно України, подано оцінку початкового вектора керувального впливу на $E$-готовність та інтерпретовано результати його застосування. Проведено моніторинг змін базисних факторів когнітивної моделі з появою нових технологій і змінами у соціально-економічному житті України.

Ключові слова: когнітивне моделювання, вектор керуючого впливу, $E$-готовність, фактори когнітивної моделі.
}

Введение. 90-е годы прошлого столетия характеризовались возрастающей коммерциализацией глобальной сети Интернет, возникновением в хозяйственной деятельности компаний и некоммерческих организаций определенных Интернет-практик. Однако вскоре выяснилось, что они не способны подменить действующие классические бизнес-процессы, т.е. отдельно бизнеса и Интернет-бизнеса как противоположных явлений не существует. Коммерциализация Интернета привела к тому, что большинство исследователей стали определять глобальную сеть как совокупность технологий, обеспечивающих $W e b$-сервисы для поддержки бизнес-процессов, голосовые и видеокоммуникации, доставку контента и функционирование социальных сетей. Это кардинально отличается от более раннего определения, в котором Интернет трактовался как гигантская мировая совокупность слабо упорядоченных каналов связи, соединяющих миллионы компьютеров. Очевидно, что сейчас Интернет-экономика как авангард информационной экономики в целом стала самостоятельным динамичным сектором, который, с одной стороны, отрицает модели традиционной экономики, а с другой - является основой изменений в ней. Однако, как и любому новому явлению, электронному бизнес-взаимодействию присущи определенные проблемы:

- необходимость повышенного доверия между партнерами, финансовых и других гарантий;
- обеспечение высокого уровня безопасности коммерческих сделок и защиты информации при этом;

- новизна и быстрая сменяемость сетевых технологий;

- нерешенность многих юридических вопросов электронной коммерции (неурегулированность на международном уровне, таможенные ограничения).

Так, для современного информационного общества главным ресурсом развития выступают знания и глобальные информационно-коммуникационные технологии, экономической базой - зрелая сервисная экономика с Интернетпрактиками, что подразумевает тотальное осознание главенствующей роли потребителя, а бизнес-приоритетным является переход от эры массового производства к эре потребителя. К сожалению, для малоразвитых в экономическом смысле стран, в том числе и Украины, без зрелости переход к «новой» экономике достаточно бесполезен и лишь усиливает недостатки отсталых хозяйственных систем. С другой стороны, проникновение Интернет-технологий в процессы государственного управления, их влияние на социальные процессы, появление представительств территориальных сообществ в сети и элементов электронного правительства в частности, электронной демократии, интернетизация взаимоотношений бизнеса с государством дает неожиданно положительные результаты даже в таких незрелых экономиках, 
как украинская. Это может послужить катализатором для вызревания в ней и Интернет-ориентированных бизнес-процессов.

\section{Актуальность}

В статье обобщены определенные результаты многолетних исследований автора по моделированию оценки готовности страны к информационной экономике (E-готовности) и обоснованию стратегии ее инфокоммуникационного развития, а также по совершенствованию инструментария такого моделирования. Актуальность выбранной проблематики и поныне обусловлена динамизмом развития современных информационных и коммуникационных технологий, а также бизнес-процессов современных предприятий, подверженных сильному инновационному влиянию сетевых технологий. Именно этот динамизм и объясняет, почему исследователям данных явлений следует пользоваться современным методическим инструментарием и разрабатывать новый.

Для описания слабоструктурированных и низкоформализованных, а также многосвязных систем большой размерности, к которым можно отнести и украинский сектор мировой информационной экономики, вполне применимы методы интеллектуального анализа и моделирования, в частности когнитивного. Проблематика такого моделирования социально-экономических систем и процессов для прогнозирования их возможного поведения и состояния в будущем исследовалась в работах [1-3]. Инструментарий когнитивного моделирования применялся украинскими и российскими исследователями, в том числе автором статьи, для обоснования сценариев возможного инфокоммуникационного развития отдельной страны, решения проблем защиты информации в Интернет-среде, обоснования тарифной политики и др. [4, 5].

Автор считает продуктивным применение когнитивного подхода в интеллектуальном моделировании социально-экономических систем и для динамического корректирования выбранного варианта национальной стратегии инфокоммуникационного развития страны с течением времени, с появлением новых технологий и тенденций развития мировой информацион- ной экономики. «Прозрачность» данного инструментария и для исследователей, и для потенциальных пользователей из государственных и коммерческих структур только подчеркивает актуальность и практическую значимость выбранной темы исследования.

Цель статьи - обобщение результатов десятилетнего мониторинга экспертной формализации когнитивной модели оценки готовности Украины к информационной экономике (E-готовности) и выявление новых значимых базисных факторов когнитивной модели состоянием на 2016 г., что позволит дать рекомендации по корректированию национальной стратегии инфокоммуникационного развития Украины на современном этапе.

\section{Постановка задачи}

Указанная цель будет реализована при решении следующих заданий:

- обобщить методику построения когнитивного графа (когнитивной карты ситуации) применительно к оценке $E$-готовности Украины;

- проанализировать отбор базисных факторов когнитивной модели готовности Украины к информационной экономике состоянием на 2006 г.;

- построить когнитивный граф такой модели состоянием на 2006 г.;

- отследить характеристики всех связей модели в матрице совместимости вершин когнитивного графа;

- описать начальный вектор управляющего воздействия $\gamma$ на процесс $E$-готовности Украины в процентах прироста влияния наиболее значимых базисных факторов на целевой;

- провести итерационные расчеты по формулам нелинейных зависимостей между факторами когнитивной модели до получения единичного значения консонанса и достоверной результатной ситуации;

- интерпретировать результатную ситуацию когнитивного моделирования оценки $E$-готовности Украины состоянием на 2006 г., найдя критическую точку влияния значимых базисных факторов модели на ее целевой фактор; 
- по результатам последующего десятилетнего мониторинга сделать выводы о практическом подтверждении полученных результатов когнитивного моделирования оценки готовности Украины к информационной экономике в 2006 г.;

- обосновать корректирующую таблицу учета приоритетов для национальной ИКТ-стратегии при достижении определенного уровня $E$ готовности страны;

- применить методику когнитивного моделирования к оценке $E$-готовности страны с учетом изменения приоритетов из корректирующей таблицы в 2016 г.;

- обосновать новый набор базисных факторов когнитивной модели оценки $E$-готовности Украины состоянием на 2016 г.;

- обобщить результаты влияния такого выбора факторов на корректирование современной ИКТ-стратегии Украины.

\section{Основной материал}

Любая «мягкая» модель в математической постановке задачи есть совокупностью «черных ящиков» с определенными входами и выходами. В этом смысле анализ больших систем способствует развитию традиционной модели управления и представляет собой совокупность «черных ящиков», функционально связанных между собой законом прохождения импульса. Для описания когнитивных моделей эффективно применяется аппарат знаковых и взвешенных ориентированных графов. Весы дуг $\left( \pm r_{1}, \pm r_{2}, \ldots \pm r_{n},\right)$ в когнитивной модели определяются или путем статистической обработки информации, или экспертно (рис. 1). Изменения в значениях факторов вводятся пошагово для определения реакции системы, после чего путем многокритериального выбора определяется множество благоприятных сценариев, которые ранжируются. Когнитивный анализ и моделирование позволяют исследовать проблему, учитывать изменения внешней среды, определяют реакцию системы. Для когнитивных моделей существует требование к их стабильности относительно разового импульсного воздействия. Так, примером импульсного воздействия могут быть события, послужившие поводом для начала первой мировой войны, развития негативных последствий второго Майдана и др.

При моделировании такие свойства процессов и явлений обеспечиваются наличием позитивных, стимулирующих рост, и отрицательных, обратных связей, а также налаживанием параметров этих связей, которые гарантируют выполнение указанных условий.

Когнитивный подход к поддержке принятия решений ориентирован на активизацию интеллектуальных процессов эксперта и помощь ему в представлении о проблемной ситуации в виде формализованной модели. Для этого применяется когнитивная карта ситуации, которая предоставляет известные эксперту основные законы и закономерности ситуации в виде ориентированного знакового графа, в котором его вершины - признаки ситуации - $\left(S_{1}, S_{2}, \ldots\right.$, $\left.S_{n}\right)$, а дуги между ними - причинно-следственные связи (см. рис. 1).

Выбор базисных факторов и объектов СЭП по методике происходит с использованием ал-

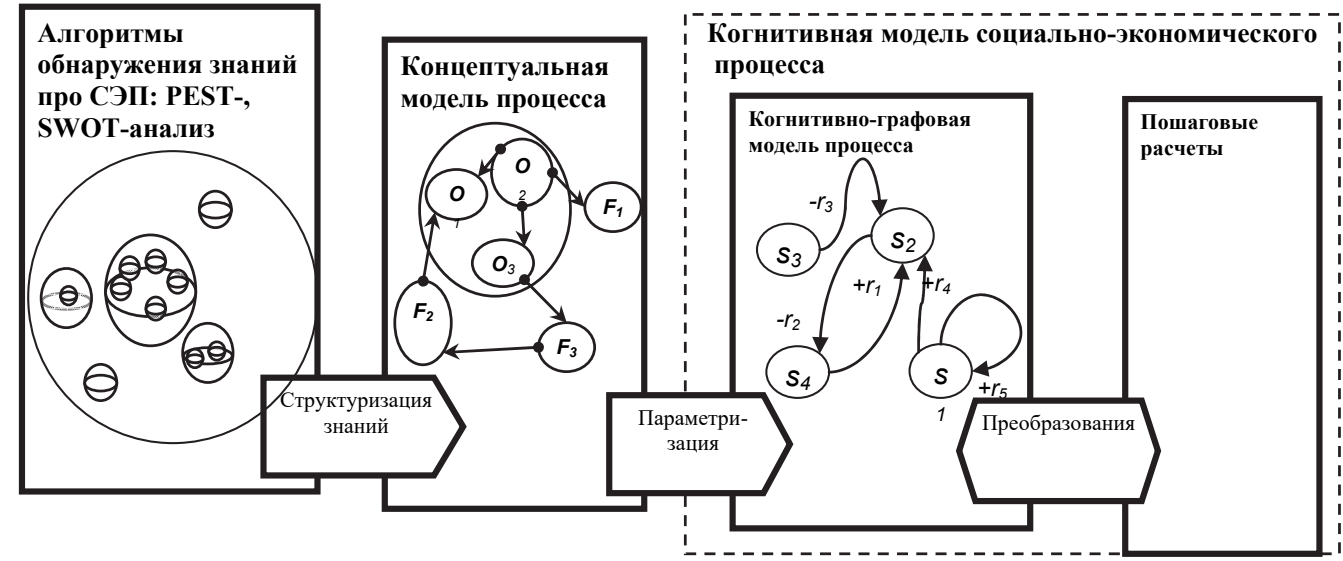

Рис. 1. Графическая иллюстрация методики когнитивного анализа и моделирования социальноэкономического процесса (СЭП) [4] 
горитма четырехэлементного стратегического анализа внешней среды - PEST-анализа (Policy политика, Economy - экономика, Society - общество, Technology - технология и наука). Ситуационный анализ проблемной области проводится посредством SWOT-анализа, позволяющего определить актуальные проблемы исследуемой области, «узкие» места, шансы и угрозы для объекта с учетом факторов внешней среды. Как указано, в когнитивной модели выделяются два типа причинно-следственных связей: положительные и отрицательные. При положительной связи увеличение значения фактора-причины приводит к увеличению фактора-следствия, при отрицательной - к его уменьшению (см. рис. 1). Когнитивный граф - это упрощенная субъективная модель функциональной организации исследуемой системы и материал для дальнейшего анализа и преобразований. Цель построения когнитивной модели заключается в генерации и проверке гипотез о функциональной структуре наблюдаемой ситуации до получения функциональной структуры, способной пояснить развитие этой ситуации с помощью прогнозирования и интерпретации качественных прогнозов развития ситуации (решение прямой задачи «что будет, если ... »), получения советов и рекомендаций по управлению ситуацией (решение обратной задачи «что нужно, чтобы ... »). Как отмечалось, итерационные изменения факторов можно проводить до фиксации определенной реакции системы (с помощью специального программного обеспечения типа Канва, Компас, Космос или по несложным алгоритмам в табличных процессорах), после чего на основании многокритериального выбора определяется совокупность благоприятных сценариев, которые упорядочиваются по рангам (рис. 2).
На рис. 3 приведен пример начального когнитивного графа модели СЭП состоянием на 2006 г. Целевым фактором когнитивной модели была определена готовность Украины к информационной экономике (Е-готовность), ее базисными факторами - уровень развития телекоммуникационной инфраструктуры, доступа в Интернет; инвестиции в телекоммуникационную инфраструктуру (государственные и негосударственные, венчурные); государственная политика поддержки телекоммуникационного бизнеса; инновации; межрегиональная дифференциация социально-экономического развития страны (в том числе цифровой «разрыв»); формирование контента Национального сектора сети.

К базисным факторам также были отнесены: недостаточность уровня культуры национального менеджмента; уровень внутренней автоматизации компаний; количество пользо-

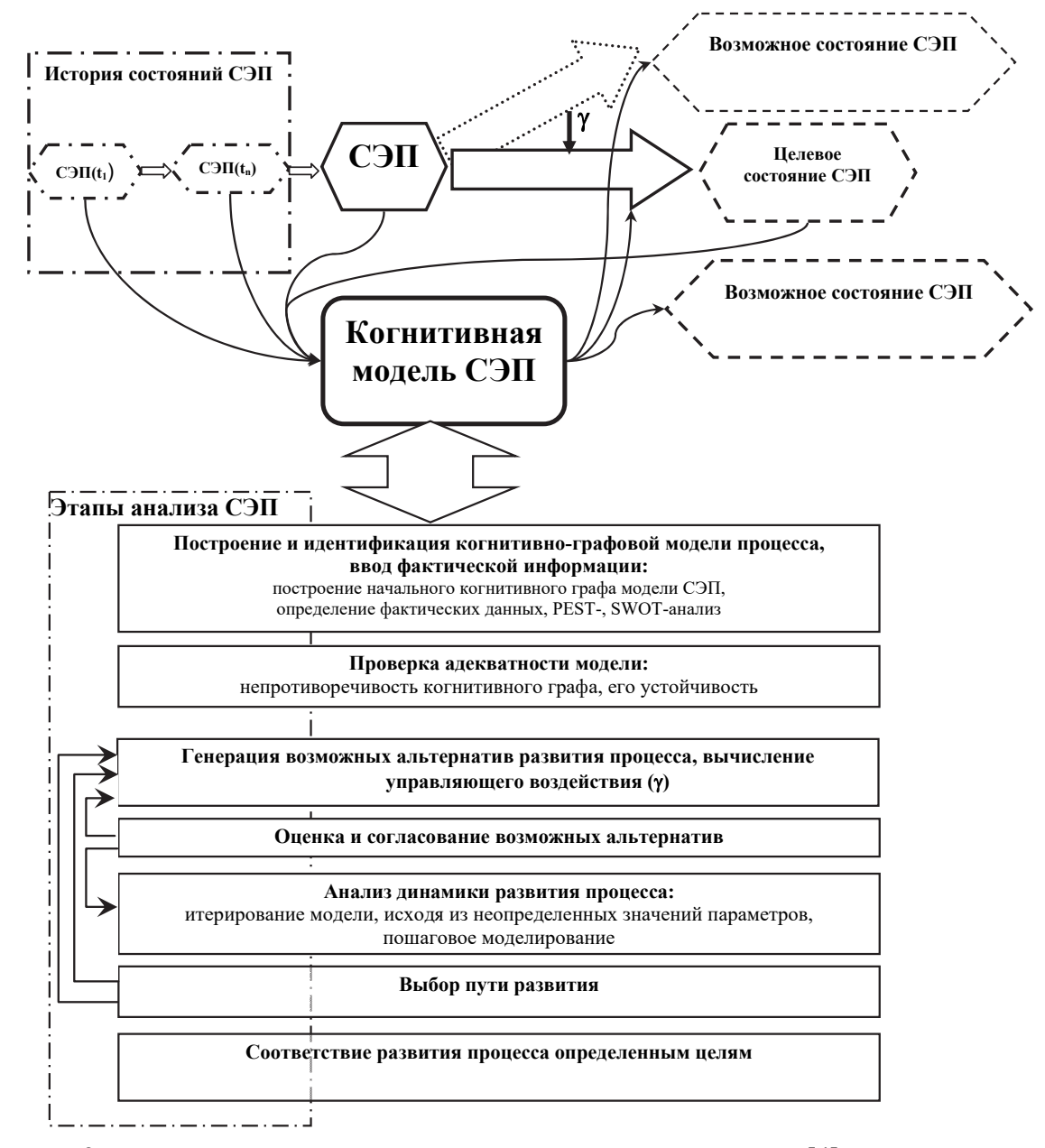

Рис. 2. Этапы анализа СЭП с применением когнитивной модели [4] 


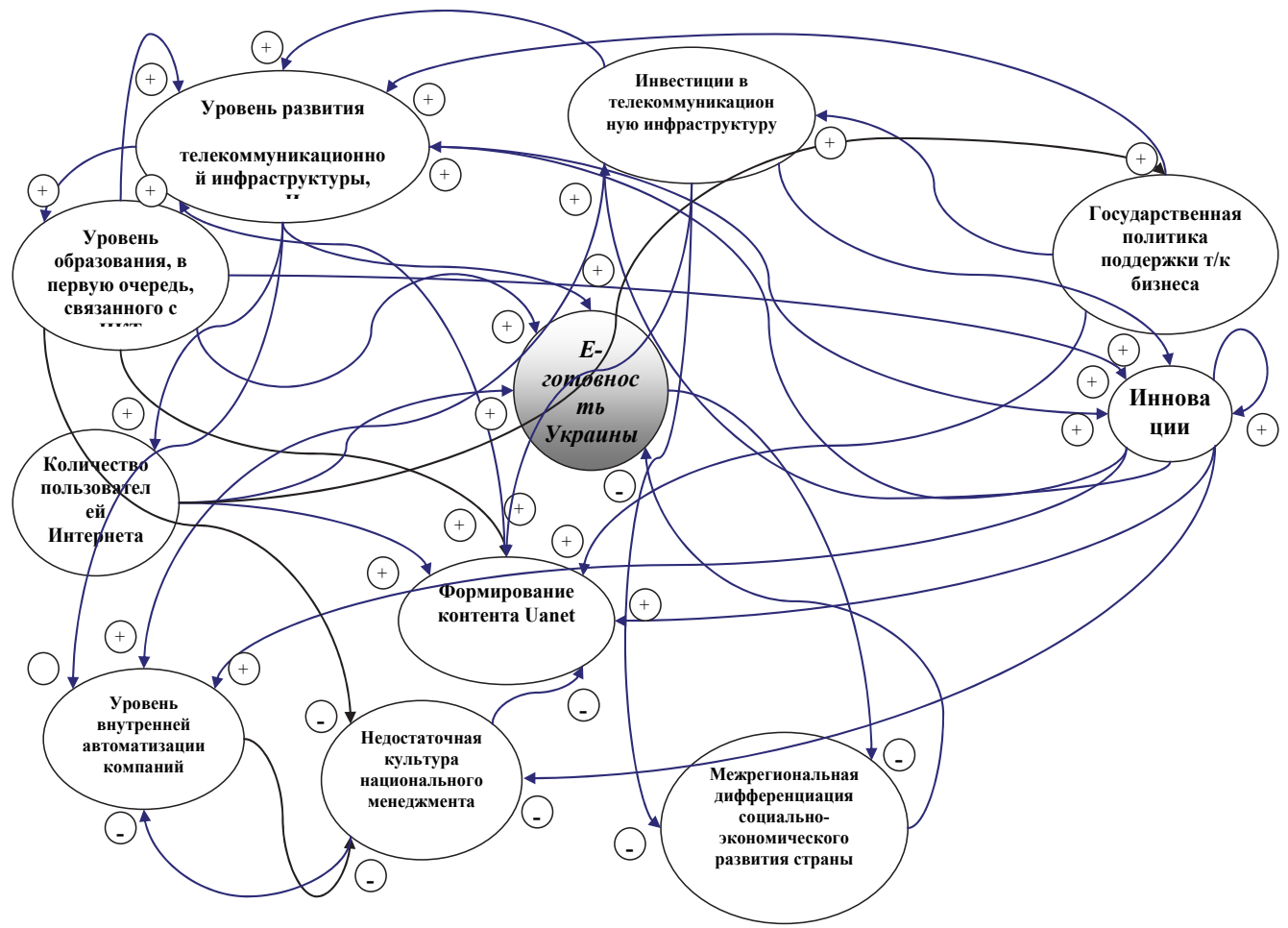

Рис. 3. Начальный когнитивний граф модели в 2006 г. [4]

вателей Интернета, их удельный вес в населении страны; уровень образования, в первую очередь, технического и инженерного, связанного с информационно-коммуникационными технологиями (ИКТ).

Целевой и базисные факторы отобраны на основании экспертной оценки, PEST- и SWOTанализа материалов предварительного исследования. При отборе учтены особенности успешного инфокоммуникационного развития североамериканских, скандинавских и южноазиатских стран, избравших определенную модель формирования информационного общества.

Выбор базисных факторов для когнитивного моделирования был достаточно прозрачным, кроме отбора фактора уровня внутренней автоматизации компаний. Включение этого фактора в когнитивную модель объяснялось подходом к электронному бизнесу, как к последней на тот момент стадии развития внутрикорпоративной автоматизации, что свидетельствовало о ее переходе на уровень внешнего взаимодействия с поставщиками и клиентами. Эта переменная, достаточно значимая для тогдашнего уровня анализа, была учтена в когнитивной модели $E$-готовности Украины-2006.

Графическое отображение связей между целевым и базисными факторами, между базисными факторами и одним из базисных факторов (инноваций) с самим собой приведено на рис. 3. Связи когнитивного графа представлены ориентированными стрелками, знаки связи - положительной или отрицательной - приведены рядом с дугами. Отследить характеристики всех связей модели удобно в матрице совместимости вершин когнитивного графа (табл. 1).

Так, отсутствие связи описывается нулевым значением элемента матрицы $\left|W_{k, m}\right|$, ее наличие, вес и ориентированность - положительным или отрицательным значением коэффициента. Все элементы матрицы совместимости по модулю меньше или равны единице, их значения определены экспертным путем по степени влияния одного фактора на другой или самого на себя.

По экспертной оценке, полученной путем двухтурового анкетного опроса специалистов ведущих IT-компаний Украины, PEST- и SWOTанализа материалов предварительного исследования, по состоянию на 2006 г. базисный фактор уровня развития телекоммуникационной инфраструктуры, доступа в Интернет влиял на целевой фактор готовности Украины к информационной экономике с весом в 0,8 балла; межрегиональная дифференциация социально-экономического развития страны - с весом в 0,1 балла; количество пользователей Интернета, их удельный вес в населении - с весом в 0,6 балла; 
Т а б л и ц а 1. Матрица совместимости вершин когнитивного графа модели, $\left|W_{k, m}\right|$ (баллы), состоянием на 2006 г. [4]

\begin{tabular}{|c|c|c|c|c|c|c|c|c|c|c|c|c|}
\hline \multirow{2}{*}{\multicolumn{2}{|c|}{ Факторы когнитивной модели }} & 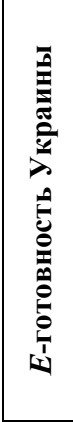 & 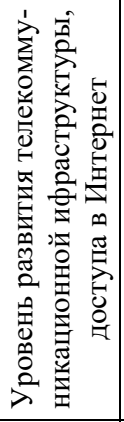 & 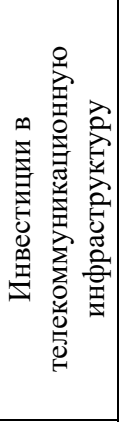 & 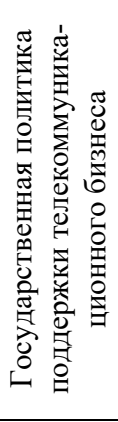 & 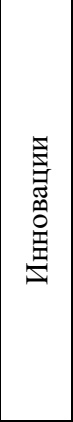 & 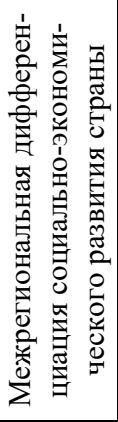 & 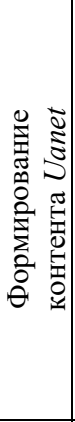 & 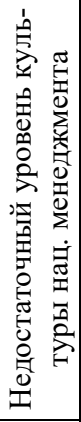 & 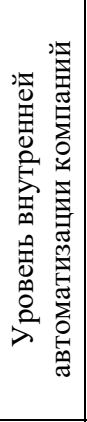 & 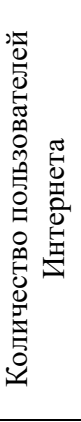 & 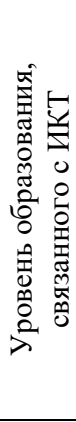 \\
\hline & & $A$ & $B$ & $C$ & $D$ & $E$ & $F$ & $G$ & $I$ & $K$ & $L$ & $M$ \\
\hline$E$-готовность Украины & $A$ & 0,0 & 0,8 & 0,0 & 0,0 & 0,0 & $-0,1$ & 0,0 & 0,0 & 0,0 & 0,6 & 0,4 \\
\hline $\begin{array}{l}\text { Уровень развития телекоммуникацион- } \\
\text { ной инфраструктуры, доступа в Интернет }\end{array}$ & $B$ & 0,0 & 0,0 & 0,9 & 0,5 & 0,8 & 0,0 & 0,2 & 0,0 & 0,0 & 0,0 & 0,4 \\
\hline $\begin{array}{l}\text { Инвестиции в телекоммуникационную } \\
\text { инфраструктуру (государственные и него- } \\
\text { сударственные, венчурные) }\end{array}$ & $C$ & 0,0 & 0,0 & 0,0 & 0,5 & 0,0 & 0,0 & 0,0 & 0,0 & 0,0 & 0,0 & 0,0 \\
\hline $\begin{array}{l}\text { Государственная политика поддержки } \\
\text { телекоммуникационного бизнеса }\end{array}$ & $D$ & 0,0 & 0,0 & 0,0 & 0,0 & 0,0 & 0,0 & 0,0 & 0,0 & 0,0 & 0,2 & 0,0 \\
\hline Инновации & $E$ & 0,0 & 0,1 & 0,8 & 0,0 & 1,0 & 0,0 & 0,0 & 0,0 & 0,0 & 0,0 & 0,6 \\
\hline $\begin{array}{c}\text { Межрегиональная дифференциация со- } \\
\text { циально-экономического развития страны }\end{array}$ & $F$ & $-0,8$ & 0,0 & $-0,7$ & 0,0 & 0,0 & 0,0 & 0,0 & 0,0 & 0,0 & 0,0 & 0,0 \\
\hline Формирование контента Uanet & $G$ & 0,0 & 0,0 & 0,9 & 0,3 & 0,2 & 0,0 & 0,0 & $-0,6$ & 0,0 & 0,4 & 0,3 \\
\hline $\begin{array}{l}\text { Недостаточный уровень культуры на- } \\
\text { ционального менеджмента }\end{array}$ & $I$ & 0,0 & 0,0 & 0,0 & 0,0 & $-0,2$ & 0,0 & 0,0 & 0,0 & $-0,3$ & 0,0 & $-0,5$ \\
\hline $\begin{array}{l}\text { Уровень внутренней автоматизации } \\
\text { компаний }\end{array}$ & $K$ & 0,0 & 0,4 & 0,8 & 0,0 & 0,6 & 0,0 & 0,0 & $-0,3$ & 0,0 & 0,0 & 0,0 \\
\hline Количество пользователей Интернета & $L$ & 0,0 & 1,0 & 0,0 & 0,0 & 0,0 & 0,0 & 0,0 & 0,0 & 0,0 & 0,0 & 0,0 \\
\hline Уровень образования, связанного с ИКТ & $M$ & 0,0 & 0,1 & 0,0 & 0,0 & 0,0 & 0,0 & 0,0 & 0,0 & 0,0 & 0,0 & 0,0 \\
\hline
\end{tabular}

уровень образования, в первую очередь, технического и инженерного, связанного с ИКТ - с весом в 0,4 балла (табл. 1). Далее, по экспертной оценке базисный фактор развития телекоммуникационной инфраструктуры, доступа в Интернет испытывал влияние других основных факторов: инвестиций в телекоммуникационную инфраструктуру; государственной политики поддержки телекоммуникационного бизнеса; инновационного развития; формирования контента Uanet как условия повышения заинтересованности инвесторов; уровня образования, связанного с ИКТ, соответственно с коэффициентами 0,$9 ; 0,5 ; 0,8 ; 0,2 ; 0,4$. Единичное значение коэффициента на пересечении строки и столбца фактора инноваций объясняется их свойством продуцировать новые инновации. По матрице отслеживаются все количественные оценки связей когнитивной модели $E$-готовности Украины по состоянию на 2006 г. (табл. 1).
Начальный вектор управляющего воздействия $\gamma$ на процесс $E$-готовности Украины описан в процентах прироста влияния базисных факторов на целевой, причем не всех, а только факторов:

- вложений в телекоммуникационную инфраструктуру с 2 процентами прироста;

- государственной политики поддержки телекоммуникационного бизнеса с 5 процентами;

- инноваций - с 2 процентами;

- уровня образования, связанного с ИКТ, - с 5 процентами (табл. 2).

Когнитивный подход к моделированию социально-экономических процессов допускает, что реальные единицы измерения факторов здесь игнорируются, а их прирост оценивается в процентах прироста их влияния на целевой фактор, причем не за определенный временной период, а в расчете на итерацию модели. 
T а б л и ц а 2. Оценка влияния прироста базисных факторов когнитивной модели на ее целевой фактор в расчете на итерацию модели, \% [4]

\begin{tabular}{|c|c|c|}
\hline $\begin{array}{l}\text { Целевой } \\
\text { фактор }\end{array}$ & $E$-готовность Украины & \begin{tabular}{|c|}
$\gamma, \%$ \\
$\mathbf{0}$ \\
\end{tabular} \\
\hline \multirow{10}{*}{ 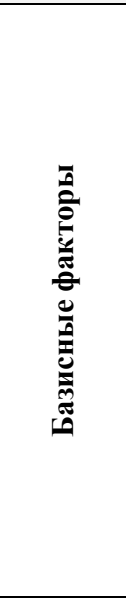 } & $\begin{array}{l}\text { Уровень развития телекоммуникационной ин- } \\
\text { фраструктуры, доступа в Интернет }\end{array}$ & $\mathbf{0}$ \\
\hline & $\begin{array}{l}\text { Инвестиции в телекоммуникационную инфра- } \\
\text { структуру (государственные, негосударствен- } \\
\text { ные, венчурные) }\end{array}$ & 2 \\
\hline & $\begin{array}{l}\text { Государственная политика поддержки теле- } \\
\text { коммуникационного бизнеса }\end{array}$ & 5 \\
\hline & Инновации & 2 \\
\hline & $\begin{array}{l}\text { Межрегиональная дифференциация социально- } \\
\text { экономического развития страны }\end{array}$ & $\mathbf{0}$ \\
\hline & Формирование контента Uanet & $\mathbf{0}$ \\
\hline & $\begin{array}{l}\text { Недостаточный уровень культуры националь- } \\
\text { ного менеджмента }\end{array}$ & $\mathbf{0}$ \\
\hline & Уровень внутренней автоматизации компаний & $\mathbf{0}$ \\
\hline & Количество пользователей Интернета & $\mathbf{0}$ \\
\hline & Уровень образования, связанного с ИКТ & 5 \\
\hline
\end{tabular}

Расчет промежуточных результатов когнитивной модели на каждой итерации осуществлялся автором в табличном процессоре $M S$ Excel (с помощью макросов) по формуле

$$
X_{m}(t+1)=W_{m, N} * X_{N}(t),
$$

где $N=k$, когда достигается $\max _{k}\left(\left|W_{m, k} * X_{k}(t)\right|\right)$ при предположении о нелинейности причинно-следственных связей между факторами, а также по формуле

$$
X_{m}(t+1)=\sum_{k} W_{m, k} * X_{k}(t)
$$

при предположении о линейности причинноследственных связей между факторами.

На двенадцатой итерации расчеты по формулам нелинейных зависимостей между факторами приостановлены при единичном значении консонанса. Получена результатная ситуация, которая, исходя из реакции системы, достоверна. Так, при начальном нулевом значении готовности Украины к информационной экономике в ситуации, описанной когнитивной моделью, при управляющем воздействии $\gamma$ на совокупность признаков (незначительном, у двух процентов для дефицитных и/или высокозатратных факторов - инвестиций, инноваций) на двенадцатой итерации она уже имела кумулятивный прирост в 374 процента.
При этом наблюдался рост уровня развития телекоммуникационной инфраструктуры на 339 процентов, уровня инвестирования в телекоммуникационную инфраструктуру - на 13 процентов, качества государственной политики поддержки телекоммуникационного бизнеса - на 36 процентов, уровня внедрения инноваций в экономику - на 458 процентов (что превышало темп увеличения целевого фактора), уровня информационного наполнения Uanet - на 121 процент, развития внутренней автоматизации компаний - на 276 процентов, количества пользователей Интернета - на 222 процента, уровня образования, связанного с ИКТ - на 19 процентов. Факторы недостаточного уровня культуры национального менеджмента и уровня межрегиональной дифференциации социально-экономического развития страны (в том числе цифровой «разрыв») сократились соответственно на 49 и 63 процента.

Проведены также альтернативные расчеты с другим набором базовых факторов и значениями их прироста в векторе начального воздействия $\gamma$. Так, в расчеты поочередно включались различные факторы, их совокупность с различными векторами начального влияния. Все они показали худшие результаты, чем приведенные ранее.

По полученным результатам когнитивного моделирования ситуации готовности Украины к информационной экономике в 2006 г. политика приоритетной стимуляции развития телекоммуникационной инфраструктуры, доступа в Интернет, вложения инвестиций в телекоммуникационную инфраструктуру; усиления поддержки государством телекоммуникационного бизнеса; внедрения инноваций; повышения уровня образования, связанного с информационнокоммуникационными технологиями, при достаточно незначительном на начальном этапе управляемом воздействии $\gamma$ на эти факторы была способна существенно продвинуть страну к информационной экономике и постиндустриальному обществу в целом.

Таким образом, из значительного числа факторов, определяющих готовность страны к возможностям информационно-коммуникацион- 
ного развития, существенными для Украины на момент десятилетней давности были:

- уровень образования, в первую очередь, технического и инженерного, связанного с сетевыми технологиями;

- инвестиции в телекоммуникационную инфраструктуру (государственные, негосударственные, венчурные);

- государственная политика поддержки телекоммуникационного бизнеса;

- инновации в телекоммуникационной отрасли.

Управление именно этими факторами в незначительных начальных диапазонах формировало критическую точку влияния на развитие $E$-готовности Украины. Ее поиск результата расчетов по когнитивной модели опирался и на научную позицию Мельника Л.Г. об информационном контроле гомеостаза системы, а именно: «Информационным контролем гомеостаза можно считать процесс поддержки состояния устойчивого равновесия на основе идеи или управляющего информационного принципа, позволяющих достигать цели с затратами вещества и энергии несоизмеримо (в несколько раз) меньше уровня метаболизма системы, то есть ее вещественно-энергетического обмена с окружающей средой. Основная цель применения управляющего информационного принципа определить такое сочетание в пространстве и времени высококачественных и низкокачественных энергетических потоков (информации, финансовых средств, вещественно-энергетических ресурсов), которое бы обеспечило минимальные затраты системы на поддержание состояния устойчивого равновесия и реализации механизмов отрицательной обратной связи.

Чтобы реализовать механизм информационного контроля гомеостаза системы, необходимо обладать спектральным зрением, позволяющим отличать информационные оттенки (степень информационности) различных элементов социально-экономической системы: материально-энергетических потоков, финансовых средств, видов информационной сущности. Эти оттенки указанных материально-ин- формационных активов определяются их местом в производственном процессе, сферой социально-экономической деятельности, фактором времени. Очень важно, чтобы спектральным зрением владели руководители всех уровней и специалисты, принимающие решения. Только искоренение информационного дальтонизма оставляет стране шанс для быстрого подъема экономики и обретения устойчивых темпов социально-экономического развития» [6].

Примененный к исследуемой ситуации инструментарий когнитивного моделирования способствовал определению именно такого сочетания факторов для выбора приоритетов инфокоммуникационного развития страны. В целом десятилетний последующий мониторинг показал, что именно влияние этих факторов позволило если и не получить «прорыв» в инфокоммуникационном развитии Украины, то, по крайней мере, показать определенные успехи в развитии национальной телекоммуникационной инфраструктуры, сохранении и развитии IT-образования, внедрении практик электронного правительства и электронной коммерции.

Предложенный инструментарий когнитивного моделирования $E$-готовности страны также пригоден для динамического отслеживания процесса и корректировки варианта национальной ИКТ-стратегии. Именно эти соображения, высказанные автором десять лет назад, подвигли вернуться к исследованиям в 2016 г., и провести обоснование подобной модели теперь.

Так, учитывая тенденции (рис. 4), сформулированы вопросы к экспертам - ведущим специалистам IT-компаний Украины, ответы на которые получены в результате двухтурового анкетного опроса в режиме «он-лайн».

В результате обобщения и статистической обработки полученных экспертных оценок, $P E S T$ - и SWOT-анализов материалов исследования предметной области, выделены несколько иные, чем десять лет назад, базисные факторы когнитивной модели $E$-готовности страны.

Так, ее первый базисный фактор 2006 г. уровень развития телекоммуникационной инфраструктуры, доступа в Интернет модифицировался через десять лет в уровень развития 
высокоскоростной цифровой телекоммуникационной структуры и уровень мобильного доступа в Интернет. Также в модель добавился базисный фактор развития социальных медиа. Сохранили свои значимые позиции факторы инвестирования в телекоммуникационную инфраструктуру, причем эксперты учитывали приоритетность и востребованность венчурного инвестирования, в первую очередь иностранного, и уровня IT-образования и общей информационной культуры населения страны.

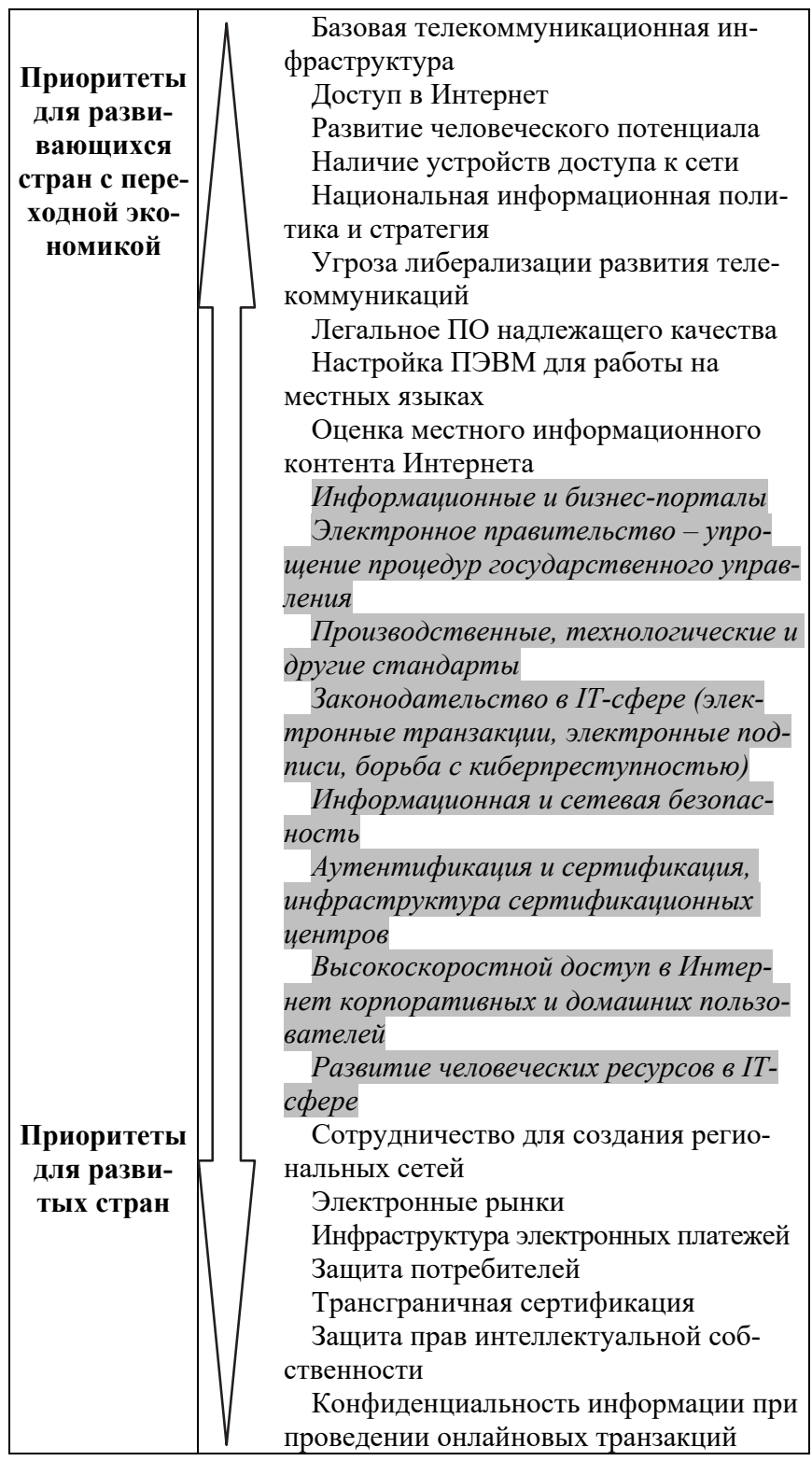

Рис. 4. Принцип учета приоритетов для обосновании национальной ИКТ-стратегии при достижении определенного уровня $E$-готовности страны (корректирующая таблица)
Масштабы и качество проведения государственной политики поддержки телекоммуникационного бизнеса получили скептическую оценку экспертов, хотя ими был предложен новый фактор, оценивающий деятельность государства по использованию телекоммуникаций - успешность становления электронного правительства. Значимость инноваций как фактора когнитивной модели в 2016 г. повысилась. Были признаны смягчившимися межрегиональная дифференциация социально-экономического развития страны (в том числе цифровой «разрыв») и острота проблемы формирования контента национального сектора глобальной сети. Недостаточность уровня культуры национального менеджмента и уровень внутренней автоматизации компаний предложено исключить из когнитивной модели. А общее количество пользователей Интернета, в том числе мобильного, их удельный вес среди населения страны по-прежнему признаны значимым базисным фактором модели.

Таким образом, матрица совместимости вершин когнитивного графа модели состоянием на 2016 г. приобрела вид табл. 3.

Заключение. Итак, последовательное решение поставленных заданий позволило прийти к следующим выводам.

Как видим, матрица совместимости вершин когнитивного графа модели оценки $E$-готовности Украины состоянием на 2016 г. существенно усложнилась, что характерно для более развитой инфокоммуникационной ситуации, в сравнении с подобной матрицей 2006 г. Этот результат исследования и представлял основной интерес.

В 2016 г. базисные факторы когнитивной модели $E$-готовности Украины стали более многочисленными, их взаимосвязи усложнились, что свидетельствует о нарастании зрелости инфокоммуникационных процессов, происходящих в стране, и необходимости смещения акцентов в национальной ИКТ-стратегии. Так, приоритетами такой стратеги, по мнению автора, должны стать:

- массовое формирование информационных и бизнес-порталов в украинском сегменте Интернета; 
Т а б л и ц а 3. Матрица совместимости вершин когнитивного графа модели, $\left|W_{k, m}\right|$ (баллы), состоянием на 2016 г.

\begin{tabular}{|c|c|c|c|c|c|c|c|c|c|c|c|c|c|}
\hline \multirow{2}{*}{\multicolumn{2}{|c|}{ Факторы когнитивной модели }} & 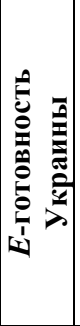 & 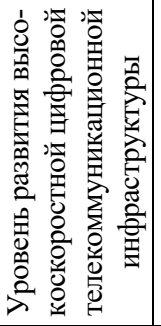 & 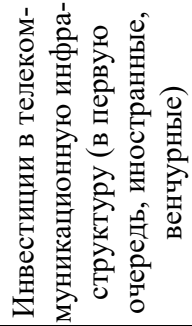 & 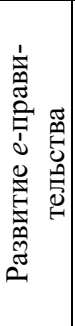 & 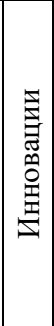 & 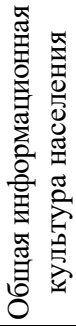 & 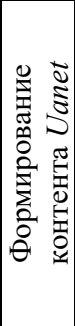 & 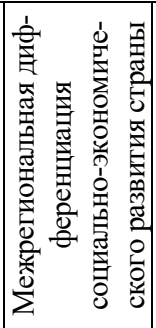 & 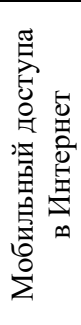 & 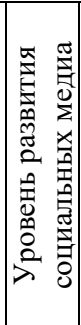 & 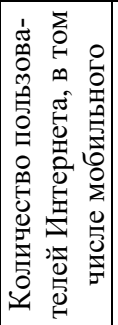 & 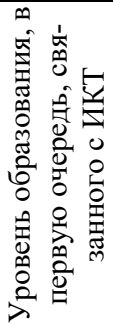 \\
\hline & & $A$ & $B$ & $C$ & $D$ & $E$ & $F$ & $G$ & $I$ & $K$ & $L$ & $M$ & $N$ \\
\hline$E$-готовность Украины & $A$ & 0,0 & 0,8 & 0,0 & 0,0 & 0,0 & 0,1 & 0,0 & $-0,05$ & 0,1 & 0,2 & 0,6 & 0,5 \\
\hline $\begin{array}{l}\text { Уровень развития высокоско- } \\
\text { ростной цифровой телекомму- } \\
\text { никационной инфраструктуры }\end{array}$ & $B$ & 0,0 & 0,0 & 0,9 & 0,0 & 0,9 & 0,0 & 0,1 & 0,0 & 0,0 & 0,0 & 0,0 & 0,3 \\
\hline $\begin{array}{l}\text { Инвестиции в телекоммуника- } \\
\text { ционную инфраструктуру (ино- } \\
\text { странные, венчурные) }\end{array}$ & $C$ & 0,0 & 0,0 & 0,0 & 0,3 & 0,0 & 0,0 & 0,0 & 0,0 & 0,0 & 0,0 & 0,0 & 0,0 \\
\hline Развитие $e$-правительства & $D$ & 0,0 & 0,0 & 0,0 & 0,0 & 0,0 & 0,1 & 0,0 & 0,0 & 0,1 & 0,0 & 0,3 & 0,0 \\
\hline Инновации & $E$ & 0,0 & 0,1 & 0,8 & 0,1 & 1,0 & 0,0 & 0,0 & 0,0 & 0,0 & 0,2 & 0,0 & 0,6 \\
\hline $\begin{array}{l}\text { Общая информационная куль- } \\
\text { тура населения }\end{array}$ & $F$ & 0,0 & 0,1 & 0,0 & 0,0 & 0,1 & 0,0 & 0,2 & $-0,1$ & 0,2 & 0,2 & 0,0 & 0,2 \\
\hline Формирование контента Uanet & $G$ & 0,0 & 0,0 & 0,9 & 0,1 & 0,2 & 0,0 & 0,0 & $-0,2$ & 0,1 & 0,5 & 0,4 & 0,3 \\
\hline $\begin{array}{l}\text { Межрегиональная дифферен- } \\
\text { циация социально-экономиче- } \\
\text { ского развития страны }\end{array}$ & $I$ & $-0,4$ & 0,0 & $-0,5$ & $-0,1$ & 0,0 & 0,0 & 0,0 & 0,0 & 0,0 & 0,0 & 0,0 & 0,0 \\
\hline Мобильный доступ в Интернет & $K$ & 0,0 & 0,0 & 0,5 & 0,0 & 0,2 & 0,2 & 0,0 & 0,0 & 0,0 & 0,2 & 0,0 & 0,0 \\
\hline $\begin{array}{l}\text { Уровень развития социальных } \\
\text { медиа }\end{array}$ & $L$ & 0,0 & 0,4 & 0,8 & 0,0 & 0,6 & 0,0 & 0,0 & $-0,3$ & 0,0 & 0,0 & 0,0 & 0,0 \\
\hline $\begin{array}{l}\text { Количество пользователей Ин- } \\
\text { тернета, в том числе мобильного }\end{array}$ & $M$ & 0,0 & 0,8 & 0,0 & 0,0 & 0,0 & 0,0 & 0,0 & 0,0 & 0,7 & 0,0 & 0,0 & 0,0 \\
\hline $\begin{array}{l}\text { Уровень образования, связан- } \\
\text { ного с ИКТ }\end{array}$ & $N$ & 0,0 & 0,1 & 0,0 & 0,0 & 0,0 & 0,0 & 0,0 & 0,0 & 0,0 & 0,0 & 0,0 & 0,0 \\
\hline
\end{tabular}

- активное становление электронного правительства для упрощения процедур государственного управления;

- принятие производственных, технологических и других стандартов, необходимых для укрепления информационной экономики;

- активная переработка законодательства в IT-сфере относительно проведения электронных транзакций, использования электронных подписей, борьбы с киберпреступностью;

- обеспечение информационной и сетевой безопасности предпринимательских структур и отдельных граждан;

- обеспечение аутентификации при проведении электронных транзакций, сертификации, развития инфраструктуры сертификационных центров;

- организация высокоскоростного доступа в Интернет корпоративных и домашних пользователей;
- развитие человеческих ресурсов в IT-сфере.

Данный вывод на этом этапе исследований самодостаточный. Дальнейшие исследования предполагают итерационные вычисления по усложнившейся когнитивной модели состоянием на 2016 г., интерпретацию результатов таких расчетов и публикацию выводов, которые будут при этом получены.

1. Евстегнеев Д., Ледащева Т. Использование когнитивных моделей при построении комплексной оценки состояния территории // Исследовано в России. МФТИ. - http://zhurnal.ape.relarn.ru/articles/ 2003/135.pdf

2. Корноушенко Е.К., Максимов М.И. Управление процессами в слабоформализованных средах при стабилизации графовых моделей среды // Труды ИПУ PAН. - 1998. - 2. - C. 34-49.

3. Кулинич А.А. Когнитивное моделирование в системах поддержки принятия решений // Междунар. конф. по проблемам управления. - Т. 3. - М.: ИПУ PAH, 1999. - C. 56-68.

Окончание на стр. 70. 
4. Макарова М.В., Лавренюк Р.М. Когнітивно-адаптивна модель обгрунтування сценаріїв інфокомунікаційного розвитку країни // Зб. наук. праць «Економіко-математичне моделювання соціально-економічних систем». - К.: МННЦ IT та С НАН та МОН України, 2010. - № 15. - С. 311-330.

5. Гинис Л.А., Чернов А.Г. Применение технологии когнитивного анализа для выработки тарифной поли- тики // Искусственный интеллект. - 2005. - № 3. C. $360-369$.

6. Мельник Л.Г. Фундаментальные основы развития. Сумы: Университетская книга, 2003. - 288 с.

E-mail:makarowa45@gmail.com (C) М.В. Макарова, 2016

UDC $334.012 .42+004.7$

\section{M.V. Makarova}

\section{An Intelligence Modeling of Information Economy E-Readiness}

Keywords: cognitive modeling, initial vector of impact, $E$-readiness factors of the cognitive model.

The article's aim is to summarize the results of the monitoring expert formalization of the cognitive readiness assessment model of Ukraine to the Information Economy ( $E$-readiness) and to identify the new significant factors of the cognitive model for 2016.

It could help to form recommendations for changes in the national ICT strategy of Ukraine.

The essential factors that determined the level of $E$-readiness of Ukraine ten years ago were: level of education, related with network technologies; investments in telecommunications infrastructure (public and private, venture capital); public policy to support the telecommunications business; innovations in the telecommunications industry. The management by these factors formed a critical point of impact on the $E$-readiness of Ukraine.

The tools of cognitive modeling are also suitable for the dynamic tracking and adjustment options of the national ICT strategy. This idea prompted the return to studies in 2016 and hold a justification of such model today.

Statistical processing of expert estimations, PEST-analysis and SWOT-analysis of the problem domain demonstrated other factors of the cognitive model of $E$-readiness of the country than decade ago.

Now, however, we were interested not so much in the results of calculating the critical point of the impact of new factors on the $E$-readiness of Ukraine at the present stage, as in the definition of the new basic factors of the cognitive model. In 2016, they have become more numerous, their relationships are more complicated that indicates the growing maturity of ICT processes in the country. This conclusion is self-sufficient at this stage of research. The future research involves forming of cognitive graph of the more complicated model, iterative calculations in the software, the interpretation of the results of such calculations and publication of the findings, which will be received. 